\title{
A QUESTÃO DOS UNIVERSAIS: SUAREZ E O NOMINALISMO
}

\author{
André Rangel Rios*
}

SINTESE - A partir do século XIV, devido em grande parte à influência de Guilherme de Ockam e à divulgação de seu pensamento, o Nominalismo torna-se corrente dominante ao se tratar do problema dos universais. No presente trabalho examina-se como a questão é colocada na obra de Francisco Suárez.

PALAVRAS-CHAVE - Francisco Suárez, universais, filosofia medieval, nominalismo.
ABSTRACT - From the fourteenth century, to a great extent on account of Occam's influence and the diffusion of his ideas, the nominalism becomes the prevalent philosophical tendency regarding the universal concepts. This paper examines how the problem is considered by the Spanish philosopher Francisco Suárez.

KEY WORDS - Francisco Suárez, universal concepts, medieval philosophy, nominalism.

Apresentarei neste artigo uma análise da questão dos universais na obra de Suarez. Esta análise possibilitará estabelecermos alguns importantes aspectos da relação de Suarez com o Nominalismo. Toda a compreensão dos universais em Suarez se baseia em sua doutrina das denominações extrínsecas. ${ }^{1}$ Como veremos, as recorrentes "hesitações" do texto suareziano quanto à questão do estatuto ontológico da denominatio extrinseca e do conceptus objectivus retornam na discussão do universale metaphysicum.

Com base nos textos de Suarez pode-se, partindo de um ponto de vista estritamente ontológico, subdividir os conceitos objetivos do seguinte modo: ${ }^{2}$ (1) Há os conceitos objetivos que são individuais: dentre os quais há (1.1) conceitos objetivos que são entes reais e (1.2) os conceitos objetivos que são entia rationis. (2) E além disso há os conceitos objetivos que são comuns ou universais: dentre os quais haveria (2.1) os conceitos objetivos universais referentes a entes reais e (2.2) os referentes a entia rationis. É certo que Suarez quase nunca fala em conceitos

* Instituto Médico Social (IN:S) da Universidade Estadual do Rio de Janeiro (UERJ).

1 Embora o presente artigo possa ser compreendido se lido isoladamente, recomendaria a leitura do meu artigo Conceito Objetivo... (Vide referências bibliográficas).

2 Sobre o conceito objetivo, o conceito formal, a denominação extrínseca e os entia rationes cf. Rios Conceito objetivo...

\begin{tabular}{|l|l|l|l|l|l|} 
VERITAS & Porto Alegre & v. 43 & $\mathrm{n}^{\mathrm{e}} 3$ & Setembro 1998 & p. 671-682 \\
\hline
\end{tabular}


universais de entes fictícios, ${ }^{3}$ de modo que em (2) ele praticamente só discute o subgrupo (2.1), ou seja, a doutrina suareziana dos universais e do processo de constituição dos universais basicamente diz respeito aos universais relativos a entes reais.

Primeiramente, cabe aqui resumir como Suarez entende o surgimento dos conceitos objetivos que se referem a um indivíduo. Os sentidos externos recebem as impressões das coisas externas e as conduzem ao sensus communis onde é processado o phantasma. O intellectus agens "purifica" o fantasma de sua materialidade física obtendo a species intelligibilis que ele dá, tal como um sêmen, ao intellectus possibilis. O intelecto possível forma - uma vez que ele, por meio da species intelligibilis, "informa" (isto é: "amolda") o ato mental - o conceito formal. Por meio do conceito formal, o intelecto humano denota a coisa. Assim, surge junto à coisa denotada o conceito objetivo correspondente ao conceito formal denotante. ${ }^{4}$ Porém o conhecimento de indivíduos não possibilita ainda nem a ciência nem a linguagem. Os universais é que são exatamente o que tornam possivel que haja tanto linguagem quanto ciência. Para Suarez, as ciências não se ocupam nem só com as palavras (voces) nem propriamente com os indivíduos, mas com os conceitos objetivos, a saber, tanto com os conceitos objetivos comuns quantos com os que se referem às coisas individuais. Dizer que as ciências se ocupam com conceitos, isto é, com conceitos objetivos, não quer dizer que as ciências se ocupam apenas com uma dimensão semântica ou intencional, pois, se assim o fosse, não haveria nenhum conhecimento que, em última instância, viesse propriamente a atingir as coisas. Ou seja, o conceito objetivo enquanto objeto da ciência é algo que 'bruxuleia' entre coisa e conceito.

A questão mais importante aqui, portanto, é a de como, após a "purificação" dos fantasmas em species intelligibiles pelo intelecto agente, surge, devido à atividade do intelecto possível, o universal. Para Suarez é apenas o intelecto possível que é apto a constituir os universais. ${ }^{5} \mathrm{~A}$ questão que Suarez propõe neste debate é a de se o universal surge com base numa abstração procedida diretamente sobre uma só species intelligibilis ou por meio do recurso a comparações dentre várias delas.

Há, para Suarez, pressupostos metafísicos que são importantes para se compreender por que ele responde aceitando a abstração direta. Tais pressupostos são os seguintes: (i) Há só coisas individuais (sejam elas coisas individuais meramente

3 DM 6,7,2: "Quod ideo in ipsis entibus rationis, quae per reflexionem et multiplicem operationem intellectus confinguntur, potest intellectus eo progredi, ut ab his etiam abstrahat rationes universales et communes, et universale conficiat etiam in rebus fictis, quae vera entia non sunt, quomodo dicunt dialectici, genus secundo intentionaliter sumptum, esse quoddam universale specificum, commune multis generibus, quae in intentione seu ratione generis solo numero differunt; et sic de aliis". O que temos aqui é uma argumentação de Suarez onde ele visa mostrar que é apenas "permissive" que os universais (no caso aqui trata-se do universale metaphysicum) podem ser considerados entes reais. Não conheço nenhuma outra passagem onde Suarez aborde a questão dos universais de entes de razão.

4 Sobre a teoria do conhecimento em Suarez cf. Müller e também Rios "Racionalidade substancial...". (Vide referências bibliográficas).

5

DM 6,5,4. 
possiveis ou de fato existentes). ${ }^{6}$ (ii) Estas cơisas são individuadas devido à própria entidade delas, ${ }^{7}$ ou seja, antes mesmo de elas serem efetivamente causadas pela onipotência divina elas já estão individuadas através de sua própria entidade, a saber, através de sua aptitudo ad esse (quer dizer: através de sua possibilidade ou essência anteriores à criação). (iii) Estas coisas individuais são também essencialmente unitárias, isto é, suas "partes" ontológicas não são realmente distintas, ${ }^{8}$ o que implica que não pode haver um universal in re realmente distinto da coisa ou das coisas. (iv) Conseqüentemente, o universal enquanto algo que participa de muitas coisas só pode existir actu se tal se der apenas objetivamente no intelecto; ${ }^{9}$ junto às coisas o que há são apenas semelhanças. ${ }^{10}$ (v) Uma vez que não há, de um modo ontologicamente positivo, espécies ou gêneros, Deus, ele próprio, não tem idéias para espécies e gêneros, ele também as conhece com base nos indivíduos possíveis. ${ }^{11}$

Antes de que eu retorne à questão da abstração direta do universal, é necessário comentar uma passagem de Suarez que pode confundir um leitor desatento:

"Principio statuendo est natura illas, quas nos universales et communes denominamus, reales esse, et in rebus ipsis vere existere; non enim eas mente fingimus, sed apprehendimus

6 DM 5,1,4: "[...] res omnes, quae sunt actualia entia, seu quae existunt, vel existere possunt immediate, esse singulares ac individuas. Dico immediate, ut excludam communes rationes entium, quae ut sic non possunt immediate existere, neque habere actualem entitatem, nisi in entitatibus singularibus et individuis, quibus sublatis, impossibile est aliquid reale manere [...]"; DM 6,1,10: "[...] extra individua nihil potest habere existentiam realem, sine qua nullum potest verum ens reale, vel actu, vel potentia [...]."

7 DM 5,6,1: “[...] omnem substantiam singularem, neque alio indigere individuationis principio praeter suam entitatem, vel praeter principia intrinseca quibus eius entitas constatat"; idem: "[...] revera non potest fundamentum unitatis ab ipsa entitate distingui".

8 DM 6,1,2: "[...] negamus enim omnem distinctionem, quae in re ipsa quovis modo actu esse possit ante mentis functionem".

9 DM 6,7,2: "[...] universale actu solum habet esse objective in intellectu; esse autem objective in intellectu, non solum veris entibus, sed etiam fictis convenire potest [...]." Aqui Suarez não está dizendo que os universais são sempre entia rationis, antes ele está dizendo que eles por vezes são entia rationis, a saber, quando se trata do universale logicum ou secunda intentio objectiva, e que por vezes eles são - ainda que apenas "permissive" - entia realia, quando se trata do universale metaphysicum ou secunda intentio formalis.

10 A similitudo não é porém, evidentemente, o universal ou a unitas universalis na coisa. A similitudo não é universal; ela inclusive existe na coisa independentemente de qualquer intelecto. DM 6,2,13: "[...] haec revera non est unitas <Sc. naturae universalis>, sed similitudo tantum; nihil enim vere unum et in re indivisum est a parte rei in hac et in illa humana natura, sed solum in hac est aliquid simile est in altera natura; haec autem non est realis unitas, sed similitudo. Unde solum possunt res plures dici a parte rei ejusdem naturae, id est similis: haec enim identitas, cum dicatur esse inter res distinctas, non potest in re ipsa quidpiam esse praeter similitudinem, ratione cujus dicuntur etiam participare, seu habere eamdem similitudinis, formaliter quidem ex vi dictae similitudinis, formaliter autem per rationem, nam definitio opus rationis est" (cf. também DM 6,4,11). Pode-se ainda indicar que a semelhança não é nada além da própria entidade da coisa; ela consiste apenas em uma aptitudo, a saber, em uma aptitudo que não é propriamente positiva, mas que consiste apenas em uma não repugnância para ter outras coisas como semelhantes (DM 6,5,3: "[...] sed solum est non repugnantia in ipsis etiam individuis, ut habere possint alia sibi similia").

11 Suarez, De divina substantia lib. 3 c.5 n.11; vol. 1 p. 212 b: "Concipiendo [sc. no que Deus apreende.... ergo singularia prout in se sunt, in eis videt similitudinem, quam inter se habent, vel integram et specificam, vel imperfectam et genericam et eodem modo, sicut non producit genera, vel species nisi in individuis, ita per eorum ideas illa producit." 
potius, easque in rebus esse intelligimus, et de illis sic conceptis definitiones tradimus, demonstrationes efficimus, et scientiam inquirimus." 12

Pela maneira como Suarez se exprime nesta passagem tem-se primeiramente a impressão de se ler uma recusa taxativa do nominalismo tradicional. Logo abaixo, porém, Suarez abranda suas palavras e esclarece que ele basicamente só é contrário ao modus loquendi dos nominalistas. Segundo os nominalistas, os universais in significando e os conceitos universais in repraesentando seriam apenas vozes (voces solum), de modo que as definiçc̃es e as ciências só se ocupariam com palavras. ${ }^{13}$ Porém, segundo Suarez, os nominalistas de fato taivez não tenham um posição điferente da dele (in re fortasse non dissident a vera sententia). ${ }^{14}$ Concluindo diz Suarez:

“[...] nam eorum [sc. dos nominalistas] rationes huc solum tendunt, ut probent universalitatem non esse in rebus, sed convenire illis prout sunt objective in intellectu, seu per denominationem $\mathrm{ab}$ aliquo opere intellectus, quod verum est [...]"15

Suarez se distancia dos nominalistas no que ele afirma que há universais nas coisas, mas aproxima-se deles no que ele só atribui os universais às coisas em função de uma denominação extrinseca. O universal em uma coisa não é senão uma presentificação intencional correspondendo a uma denominação extrínseca de um conceito formal universal. Nada é propriamente acrescentado à coisa, sendo que esta presentificação intencional só se dá enquanto o ato mental denota através de seu conceito formal a coisa ou as coisas.

Cabe destacar aqui quatro importantes questões com as quais Suarez se ocupa em sua doutrina dos universais: (i) Se os universais são apenas palavras. (ii) Se os universais são entia rationis ou algo real na coisa. (iii) Quais são então os três tipos de universais. (iv) Dado que há três tipos de universais, qual é o tipo mais fundamental e quais, e sob que circunstâncias, se pode falar em universais que são entia rationis e que são realmente nas coisas. Suarez, porém, não se ocupa, ao menos explicitamente, com a questão de por que não se deve atribuir aos universais um estatuto ontológico intermediário. $\mathrm{O}$ certo é que ele recusa um tal estatuto ontológico intermediário, a saber, ele o recusa tanto para os universais quanto para qualquer outra entidade. No caso dos universais ele rejeita que se os hipostasie de qualquer modo que seja; ele diz que só em função da eternidade do intelecto divino é que se pode falar em universais eternos. ${ }^{16}$

Como já indiquei em um outro texto, ${ }^{17} \mathrm{o}$ que pode ser entendido como ontologicamente indefinido em Suarez é o estatuto ontológico da denominação extrínse-

12 DM 6,2,1.

13 Idem: "[...] Nominalibus [...], qui voces solum aiunt esse universales in significando, et conceptus universales in repraesentando, et circa hos proxime versari definitiones et scientias, ut videre licet in Ocham, in 1, distinct. 2, quaest. 4, et Quodlib. 5, quaet. 12 et 13; et Gabr. [...], quos late impugnat Fonseca [...]."

14 Idem: "Et merito reprehendi sunt [sc. Nominales] quoad aliquos loquendi modos, nam in re fortasse non dissident a vera sententia [...]"

15 Idem (grifado por mim).

16 DM 6,8,7: “[...] ideo existimo universalia non posse dici aeterna illo modo, nisi in ordine ad aliquem intellectum, qui aeternus sit [...]."

17 Rios Conceito Objetivo... 
ca. Não que ele próprio entenda que a denominação extrínseca é ontologicamente indefinida; ele propõe que ela seja de alguma maneira redutível à realidade, ou à realidade de seu fundamento ou à da coisa denominada. ${ }^{18}$ Porém, se a sua posição quase programática rejeitando qualquer domínio intermediário entre o nada e o real (non enim medium datur inter esse fictum et reale) ${ }^{19}$ é, por um lado, afirmada com clareza, ela, por outro lado, nunca deixa de vir acompanhada por uma argumentação eivada de hesitações e reservas. A denominação extrínseca, ou seja, a dimensão semântico-intencional que ela inclui, tanto é quanto não é, embora ela não chegue a ser dita nada. Assim, o conceito objetivo (que é o que corresponde, junto à coisa, à denominação extrínseca) tem, por um lado, tanta realidade quanto a coisa denotada tem realidade; por outro lado, não é senão objetivamente no intelecto. Ele é tanto um objeto apreendido quanto uma apreensão (conceito) objetiva. O que é para nós importante, no momento, é que esta "oscilação" própria a sua doutrina do conceito objetivo também se encontra em sua doutrina dos universais, pois a universalidade dos universais também deve ser considerada uma denominação extrínseca.

Retornemos agora à questã̀o do surgimento dos universais. Cabe lembrar que as relações predicamentais (que só podem ocorrer entre duas coisas atuais) ${ }^{20}$ não são indispensáveis para o surgimento dos universais. Pode-se vir também a forjar universais com base em coisas possiveis. As coisas possiveis guardam umas a respeito das outras as mesmas proporções que as coisas atuais. ${ }^{21}$ Embora a nãoatualidade das coisas possíveis exclua uma condição essencial para o surgimento de relações predicamentais de semelhança, não fica excluído o surgimento de conotações $^{22}$ de semelhança. Cada coisa, atual ou possivel, difere de uma outra coisa totalmente e é por si mesma totaimente individualizada. Em si, uma coisa, uma vez que ela é por si própria totalmente individualizada, não tem nada em comum com qualquer outra coisa por mais semelhante que esta outra coisa possa ser com ela. Ao menos até que algum intelecto se ponha a agir, não há nas coisas, que são individuadas e independentes, qualquer universalidade. A universalidade que Suarez "expulsa" assim energicamente das coisas "ressurge" em volta das coisas como conotações. Contudo, as conotações não são ontologicamente algo e não acrescentam qualquer realidade às coisas. Não são, portanto, nada de positivo, o que não impede que as conotações de semelhança, isto é, a conveniência entre as coisas (similitudo aut convenientia) seja o que assegure a unidade do conceito formal e possibilite ao intelecto que ele abstraia o conceptus objectivus communis. Sendo assim fica esclarecido que não é certo dizer que o intelecto abstraia o universal da coisa, mas, antes, deve-se dizer que ele constitui (facit) os

18 Idem p. 731 e seg.

19 Suarez De anima lib. IV c. 3 n. 26 (Opera Omina).

20 Sobre a doutrina de Suarez a respeito das relações predicamentais cf. Rios "Verdade e adaequatio..." e Die Wahrheit... § 10.

21 DM 6,3,7: "[...! eadem est proportio rerum possibilium inter se, quae est existentium inter se [...]."

22 As conotaçôes têm de ter na metafísica de Suarez o mesmo estatuto ontológico das denominaçōes extrínsecas; as conotações, de um ponto de vista ontológico, seriam em última instância denominações extrinsecas dotadas de reciprocidade. Sobre isto cf. Rios "Verdade e adaequatio..." e Die Wahrheit... §§ 10- 11. 
universais com base nas semelhanças e por meio das denominações extrinsecas. ${ }^{23}$ Este "constituir" não é, porém, nada além de uma explicitação por meio de uma denominação extrínseca (ou seja, trata-se, em última instância, de uma explicitação semântica). ${ }^{24}$

Vendo-se assim, pode ser que se pense que o surgimento dos universais se dá antes por meio de comparações do que por meio de uma abstração direta. Contudo, Suarę indica que uma operação reflexiva pressupõe uma operação direta (operatio reflexa supponit directam). ${ }^{25}$ Sua posição é a de que uma natura communis pode ser abstraída de uma coisa sem qualquer comparação com outras ${ }^{26}$ e que a comparação só é imprescindivel para a constituição do universale logicum que é, aliás, um ens rationis. ${ }^{27}$ Para nós hoje, de fato, é difícil compreender por que Suarez preferiu, na formação dos universais, a abstração em detrimento à comparação. Para nós hoje, de certo modo, não chega a ser incômodo que aceitemos processos infinitos que têm como conseqüência inclusive que a origem se torne longínqua e inacessível; Foucault veio mesmo a considerar que este distanciamento (recul) da origem é uma das características constitutivas da épistème moderna. ${ }^{28}$ Mas para Suarez, p. ex., a hipótese de que tudo o que nós dizemos ou apreendemos se liga a uma cadeia infinita de interpretações e que nunca alguém veio a apreender ou a dizer algo de um modo totalmente destituído de preconceitos, é inaceitável. Para ele, ao contrário, é necessário que haja uma origem. A aceitação de processos ad infinitum não é algo satisfatório pois um escolástico parte do principio de que o que tem de ser esclarecido é o início, isto é, a origem, após a criação do mundo, do conhecimento e da linguagem. Dizer, assim, que nós abstraímos os universais devidọ a termos sempre já um background de conceitos gerais os quais tanto nos possibilitam a abstração quanto também pode vir a nos desencaminhar (um preconceito qualquer, errôneo mas ensinado pela tradição, pode nos levar a apreender

23 DM 6,3,11: "[...] ad unitatem conceptus formalis, satis esse ut ex parte objecti supponatur unitas fundamentalis conceptus objectivi, quae consistit in similitudine seu convenientia plurium singularium in unitate formali; nam hoc satis est ut intellectus sua vi et efficacia intelligendi possit abstrahere conceptum objectivum communem; unde quoad hanc praecisionem talis objecti communis et universalis, intellectus non supponit objectum suum, sed facit, seu potius confert illi statum illum praecisionis per extrinsecam denominationem."

Cf. a última frase da citação acima: "[...] seu potius confert illi statum illum precisionis per extrinsecam denominationem."

25 DM 6,7,2: "Quia vero cognito intellectus incipit necessario a realibus entibus, tum quia operatio reflexa supponit directam, tum etiam quia ficta entia non concipiuntur, nisi per aliquam habitudinem, vel proportionem ad vera entia, ideo recte etiam dicitur, ea universalia esse entia realia, quae per directam operationem intellectus abstrahi possunt."

DM 6,6,11: "Primo enim abstrahi potest natura communis per puram praecisionem naturae ab uno inferiori absque ulla comparatione, vel superioris conceptus ad aliquem inferiorem, vel ipsorum inferiorum inter se, ut quando a solo Petro simpliciter praescindo individuantes proprietates, et sisto in humanae naturae consideratione."

27 Loc. cit. n. 10: "At vero loquendo de relatione universalitatis prout a nobis concipitur ad modum relationis secundum esse, haec non potest resultare per solam abstractionem, sed eo modo quo est, fit per comparationem, quia, ut suppono, haec relatio non est realis, sed rationis; ergo non est in natura ipsa dum absolute et abstracte cogitatur, quia ex vi illius actionis, illa non refertur per intellectum, quia intellectus nondum comparat illam ad sua inferiora, neque etiam refertur realiter, ergo nondum est talis relatio". Loc. cit. n.12: “[...] haec comparatio ut sic non pertinet ad constituitionem universalis, sed ad considerationem cujusdam relationis mutuae inter ipsa particularia." Foucault Les mots... cap. IX, VI "Le recul et le retour de l'origine" p. 339 e seg. 
um coisa de um modo falso) é, para Suarez, inaceitável. Para ele há que se poder indicar um momento no tempo onde tudo se inicia, de onde se parte do zero. Esperar de Suarez que ele aceite o postulado de uma relação dinâmica entre os conhecimentos já adquiridos e a consumação de juízos verdadeiros é incongruente com o que se tem como pressuposto em sua época. Mas, uma vez que há que se buscar em Suarez um início determinado no tempo, que só uma tal origem é pensável para ele, então podemos compreender melhor que ele privilegie a abstração direta: É, de fato, para nós, estranho aceitar que se possa, conhecendo-se apenas um indivíduo, digamos, o indivíduo Pedro, sem compará-lo com os demais homens, vir a abstrair o universal Homem. No entanto, esta é a doutrina de Suarez.

Analisemos agora uma importante passagem do De anima de Suarez:

Segundo o manuscrito de Suarez: "Primum [sc. a natureza universal] est realiter in ipsa natura et cognoscitur $a b$ intellectu directa cognitione, quae solet dici prima intentio seu conceptus formalis; et natura sic cognita solet dici prima intentio objectiva."

Segundo a edição de B. Alvarez: "Primum [sc. a natureza universal] realiter datur in natura, seu ipsa est natura, cognosciturque ab intellectu directa cognitione, quae solet dici prima intentio, seu conceptus formalis: natura vero sic cognita prima intentio objectiva, sive objectivus conceptus"29 (o grifo è meu).

Compreendo esta passagem do seguinte modo. Se nós apreendemos Pedro enquanto homem, então o conceito formal "homem" denota, por um lado, Pedro extrinsecamente e, por outro lado, surge uma relação transcendental, a saber, enquanto esta denotação, isto é, este conhecimento, de fato é adequado à coisa. Mas, na medida em que nós consideramos Pedro apenas sob a designação "homem" e a designação "homem" é empregada apenas a respeito do indivíduo Pedro sem qualquer pretensão à universalidade, embora o conceito "homem" inclua uma certa universalidade, nós podemos falar em uma prima intentio formalis (isto é, conceptus formalis), que conhece (denota) a coisa, e de prima intentio objectiva (isto é, conceptus objectivus). Suarez não usou em seu manuscrito o termo conceptus objectivus e Elorduy pensa que Alvarez o interpolou de um modo erôneo. Não vejo, porém, aqui nenhum problema maior. Elorduy entende o conceito objetivo como sendo um terceiro gênero de realidade, ou seja, um gênero autônomo de realidade ("un tercer género de realidad") ${ }^{30}$ e não crê que seja correto se compreender o conceito objetivo apenas como aquilo junto à coisa a que o ato mental alcança. Elorduy propõe uma interpretação de Suarez que não chega a diferenciar suficientemente a posição de Suarez da de Caetano. ${ }^{31}$ Segundo Caetano - assim creio poder resumir esta discussão - o conceito objetivo seria a mesma coisa que vim a reconhecer em Suarez como sendo o conceito formal enquanto imago, ${ }^{32}$ isto é, o conceito formal enquianto se está considerando o seu conteúdo semânticointencional. $\mathrm{O}$ que Elorduy parece nem de longe estar se dando conta é que o conceito objetivo de Suarez "oscila" entre conceito e coisa. Elorduy busca dar uma solução para este "oscilar" no que ele fala em um terceiro reino de realidade. Com

Citado em Elorduy p. 351-352.

Eiorduy p. 373.

Loc. cit. p. 348-351.

32 Cf. Rios Conceito objetivo... p. 721 e seg. 
isso ele pratica uma violência ao texto e ao pensamento de Suarez, pois todo o cuidado de Suarez foi o de evitar "dar uma solução" para esta questão, não que ele não tenha dito com clareza qual seja a sua posição (para ele a denominação extrínseca pode ser reduzida à realidade ou de seu fundamento ou à da coisa denotada), mas ele sempre argumentou com reservas e lacunas. Suarez não só negou em seu texto qualquer coisa como um terceiro reino de realidade quanto não chegou a dar uma solução à questão, ele manteve nas argumentações a ambigüidade. Sem dúvida, é também ambígua a forma como Suarez mantém a ambigüidade ou duplicidade de sua discussão sobre o conceito formal e o conceito objetivo, mas foi só através de duplicidades e da aceitação/dissimuiação destas duplicidades com outras duplicidades que a metafísica pode manter o seu projeto de fechamento. Elorduy, digamos ingenuamente, crê no projeto de fechamento e crê que o postulado de um terceiro reino de realidade vai possibilitar a Suarez realizá-lo de um modo mais seguro e livre de duplicidades. Mas a destruição das duplicidades tornaria o próprio projeto de fechamento inviável, pois o fechamento só se dá enquanto projeto sempre incompleto (sempre recorrendo a suplementos). A originalidade e a força do pensamento de Suarez está em como ele, ao não solucionar, soluciona a questão do estatuto ontológico do conceito objetivo (e da denominação extrínseca), em como ele indica o fechamento mas nunca o conclui. Elorduy não reconhece a duplicidade da doutrina de Suarez sobre o conceito objetivo/conceito formal como sendo incontornável; ele buscou em todos os cantos da obra de Suarez uma passagem que lhe desse base para eliminar esta duplicidade (não me parece que ele tenha procurado ver, tal como fiz, que esta duplicidade surge em várias outras passagens), ele crê ter achado tal trecho neste manuscrito. Para Elorduy, o discipulo Alvarez teria desvirtuado a obra do mestre introduzindo nela uma duplicidade inaceitável. Mas não será que é o discípulo Elorduy que está desvirtuando a obra do mestre ao querer retirar dela uma duplicidade incontornável? Penso que o fato de Suarez não ter usado o termo conceptus objectivus nesta passagem em seu manuscrito, isto é, num texto não estabelecido por ele em sua forma definitiva, não tem nada de particularmente significativo e que prima intentio objectiva e conceptus objectivus são termos sinônimos para Suarez.

Deste modo temos, em um primeiro momento, por um lado, o conceito objetivo "homem" no que ele diz respeito à coisa, isto é, na medida em que ele só se refere ao indivíduo Pedro, e, por outro lado, o conceito formal "homem" no intelecto (não é importante se o conceito formal está só em um ou em mais intelectos pois Suarez pressupõe tacitamente que os conceitos formais "homem", ainda que ontologicamente numerosos, são semântico-intencionalmente unitários). ${ }^{33}$ Mas há ainda que se esclarecer como o conceito "homem" é apreendido em sua universalidade. Isto se dá por meio de reflexão. Há aqui dois modos de reflexão, sendo que o primeiro modo é um pressuposto para o segundo modo. ${ }^{34}$

33 Rios Conceito objetivo... p. 725 e seg.

34 DM 6,6,10: "Quia nihil obstat quod eidem naturae possit per intellectum convenire duplex ratio universalitatis, absoluta, scilicet, et respectiva, et quod illae per diversas operationes intellectus fabricentur, et quod una, scilicet, quae absoluta est, sit proximum fundamentum alterius, scilicet, relativae." 
Primeiro modo de reflexão: No que são comparados vários indivíduos (conferendo Petrum cum Paulo) a respeito da natura humana (tal comparação só pode ocorrer com base no primeiro momento em que o intelecto agiu diretamente) e no que, por meio desta comparação, a semelhança destes indivíduos, na medida em que são homens, vem a ser explicitada, surge a secunda intentio formalis que consiste na generalidade destes indivíduos no conceito "homem", isto é, na denominação extrínseca deste conceito "homem" a respeito dos diferentes individuos. Este primeiro modo de reflexão é, porém, só uma reflexividade in actu exercito $0^{35}$ e não produz deste modo nenhum ens rationis.

Segundo modo de reflexão: No que se ficcionaliza ${ }^{36}$ que algo corresponde ao predicado "homem" junto aos individuos, surge o universal explicitado em sua universalidade como uma coisa que persiste objetivamente frente ao intelecto. Neste segundo modo de reflexão trata-se de uma reflexividade in actu signato, de modo que ela produz entia rationis. Enquanto a secunda intentio formalis consiste em uma notitia praecisiva vel comparativa, isto é, ela é o conhecer in actu exercito a denominação extrínseca de um conceito formal comum, ${ }^{37}$ a secunda intentio objectiva consiste em uma notitia magis reflexa, ${ }^{38}$ isto é, ela é o conhecer in actu signato o denotar de um conceito formal comum - o que, conseqüentemente, produz entia rationis.

Fica assim bem esclarecido que Suarez não aceita o aparente paralelo entre conceptus formalis/conceptus objectivus, por um lado, e secunda intentio formalis/secunda intentio objectiva, por outro lado. A secunda intentio objectiva não corresponde à secunda intentio formalis tal como o conceptus objectivus corresponde ao conceptus formalis. A secunda intentio objectiva é constituida, isto é, ficcionalizada, por meio de uma reflexão in actu signato que a produz enquanto um ens rationis. $\mathrm{O}$ conceito objetivo surge por meio de uma denotação direta e extrínseca do conceito formal, ou seja, ele não é propriamente nem causado ontologicamente nem ficcionalizado.

Suarez distingue três gêneros de universais: 1) O universal da prima intentio objectiva junto à coisa, isto é, do conceito objetivo enquanto ele diz respeito a um indivíduo; este universal é também chamado de universale physicum ou in re. 2) 0 universal da secunda intentio formalis ou universale metaphysicum ou ante rem que é, a saber, um reale aliquid. 3) O universal da secunda intentio objectiva ou universale logicum ou post rem que é uma relatio rationis, isto é, um ens rationis. ${ }^{39}$

$\mathrm{O}$ universale physicum não é propriamente um universal. A ele não cabe nenhuma universalidade. Sem dúvida, ele é algo real na coisa mas não é algo universal uma vez que ele é exatamente tão individual quanto a coisa na qual ele está e

Sobre a reflexividade in actu exercito e in actu signato cf. Rios "Verdade e adaequatio...".

36 Uso "ficcionalizar" como traduçấc de fingere. Notar que fingere não é necessariamente "imaginar"; "imaginar" é apenas um tipo de "ficcionalizar". Sem dúvida, um ente imaginado é um ens rationis, mas há ainda outros tipos de entia rationis que não são imaginados tais como o matrimônio entre duas pessoas, a relação de senhor e escravo etc. DM 6,6,10-11 e DM! 6,7,2.

DM 6,6,12

39 Suarez De anima lib. 4 c. 6 nn. 22-23 e DM 6,8,3-4. 
da qual ele só se distingue ratione ${ }^{40} \mathrm{~A}$ universalidade só se dá, para Suarez, objetivamente no intelecto, isto é, ou em 2, enquanto um conceito objetivo, ou em 3 , enquanto um ens rationis. ${ }^{41}$

O universale logicum não é, contudo, propriamente o objeto da lógica. O lógico (dialecticus) tem a tarefa de conduzir a atividade do intelecto a respeito de definiçōes, distinções, argumentações e demanstrações, sendo que ele vem então a levar em conta as denotações que se devem aos atos mentais. Certamente, porém, a discussão de como se dá o surgimento desses universais e qual seja o seu estatuto ontológico é uma questão tanto para os metafísicos quanto para os físicos. ${ }^{42}$ O lógico ocupa-se apenas com o modus sciendi. Diferindo da lógica, as outras ciências se ocupam com conceitos objetivos sob os quais se incluem tanto os conceitos objetivos que se referem isoladamente a individuos quanto os conceitos objetivos universais que se referem a vários indivíduos ao mesmo tempo. Os conceitos objetivos não desempenham aí um papel univoco, eles são tanto aquilo através do que o intelecto humano alcança as coisas quanto as coisas mesmas. Com o conceito objetivo "homem" nós não conhecemos nem o indivíduo Pedro nem todos os indivíduos de toda a história do mundo na totalidade deles, embora isto que chegamos a conhecer deles não seja uma ficção, mas algo verdadeiro. 0 conceito objetivo possibilita que nós, apesar da finitude de nosso intelecto, cheguemos a um conhecimento verdadeiro. Embora nós, ao contrário do que acontece com Deus, não possamos conhecer nem cada indivíduo exaustivamente nem a totalidade dos indivíduos também exaustivamente, isto é, em todas as situações possíveis em todos os mundos possiveis, nós podemos formular por meio de representações intencionais adequadas dos indivíduos e universalizações adequadas proposições verdadeiras e constituir domínios científicos. Nosso conhecimento seria assim incompleto mas não seria falso. Toda a discussão da verdade das proposições bem como a discussão dos universais (que são pressupostos para a formação de grande parte das proposições) pressupõe e visa fundamentar a possibilidade de uma verdade, da verdade do conhecimento humano, que não é tão completa quanto a que Deus tem com sua intuição infinita, mas que não é menos

40 DM 6,8,3: "Rursus universale physicum dici potest natura ipsa universalis prout in rebus existit; et hoc modo non sumitur universale formaliter, ut universale est, sed solum materialiter, pro natura, quae potest abstrahi et universalis denominari. Dicitur autem hoc universale physicum, quia cum sit in rebus ipsis singularibus contractum, subjectum est mutationi, et accidentibus sensibilibus a quibus physica consideratio incipit."

41 DM 6,7,2-3: "Dupliciter enim diximus, naturam posse denominari universalem, primo, denominatione absoluta, ac si universaliter subsisteret; secundo, denominatione respectiva. Priori modo non est universalitas ens rationis, tanquam aliquid proprie confictum a ratione, sed solum tanquam denominatio extrinseca proveniens ab actu rationis... Posteriori autem modo loquendo de universali relative, seu de relatione universalitatis, satis ex dictis constat universale non esse ens reale, quia illa relatio non est realis, sed rationis."

42 DM 6,8,4: "Universale autem logicum dicitur ipsum universale in actu, quod per operationem intellectus consurgit; nam quia dialectici munus est operationes intellectus dirigere in ordine ad definitiones et argumentationes, seu demonstrationes recte et ordinate conficiendas, quae potissime traduntur de rebus universaliter conceptis, et inter se comparatis et coordinatis, ideo necesse est ut intentiones rationis seu denominationes inde consurgentes consideret, quanquam non ita hoc est proprium dialecticis, quin magis proprie ac per se possit ad metaphysicum pertinere; et aliquo etiam modo ad physicum." 
verdadeira apesar da incompletude. Como indiquei num outro artigo, ${ }^{43}$ a aceitação da verdade das proposições, isto é, da verdade que o intelecto humano chega a alcançar, como tão verdadeira quanto a verdade do conhecimento divino não vai sem "duplicidades"; "duplicidades" que também estão relacionadas às "duplicidades" do conceito formal/conceito objetivo.

A duplicidade da doutrina suareziana do conceito formal/conceito objetivo leva a que ele negue formalmente que haja uma dimensão semântica autônoma mas aceita nas argumentações conceder certa autonomia quer ao conceito formal quer ao conceito objetivo. Assim o conceito formal, ora é pensado como sendo uma qualidade inerente ao intelecto, ou seja, haveria tantos conceitos formais quanto há intelecto, ora é pensado como sendo algo de comum às várias coisas que são denotadas através dele. Suarez quase nunca se preocupou em esclarecer este seu pressuposto tácito de que há uma unidade semântica na pluralidade física dos conceitos formais. Pode-se dizer que ele nunca se viu obrigado a fazê-lo, ou seja, é porque a duplicidade de fato funciona em suas argumentações que ele só poucas vezes se vê obrigado a "hesitar". E há só uma passagem em que Suarez, fugidiamente, indica o processo de abstração e as semelhanças como as garantias últimas da unidade do conceito formal. Mas não creio que isto possa ser tido como satisfatório pois afinal o processo de abstração é algo "físico" que se dá em diferentes processos.

O que foi dito até agora nos permite concluir que a origem da universalidade dos universais está no universale metaphysicum. Nós devemos considerar a universalidade do universale logicum como secundária em relação à universalidade do universale metaphysicum. $\mathrm{O}$ universale metaphysicum surge não de uma comparação entre conceitos que se referem a indivíduos, mas diretamente do processo de abstração e deve assim ser compreendido como sendo um conceito formal.

O problema aqui é que se Suarez afinal entende o conceito formal como sendo algo físico na alma, então ele, para evitar um confiito muito claro, ainda tem de indicar um outro lugar onde se possa dizer que está a universalidade dos universais. E, de fato, ele propõe que o universal é uma denominação. A secunda intentio formalis tem de ser compreendida como sendo um conceptus formalis communis (na medida em que este conceito é considerado apenas segundo a sua face semântica, isto é, na medida em que ele é um conteúdo semântico), que é conhecido in actu exercito. Ontologicamente a intentio secunda também não é nada mais do que uma denominatio extrinseca. Uma denominação extrínseca, na medida em que ela é algo semântico, não é nem um ens reale nem um ens rationis, embora Suarez, apesar das "hesitações", busque reduzir a denominação extrínse$\mathrm{ca}$, ou à realidade do fundamento, ou à realidade da coisa denotada. Contudo, a discussão minuciosa que empreende dos universais nas DM o levou a conceder de um modo bem discreto (ou seja, trata-se aqui de mais uma "hesitação" sua) que o universale metaphysicum não é nem algo que existe atualmente (non dicunt aliquid existens realiter) nem é um ens rationis (nec proprie dicuntur aliquod ens rationis). Mas não se deve aqui forçar o texto de Suarez e querer entender que ele esteja aceitando um terceiro reino de realidade. Como já disse, não é mais do que

Rios "Verdade e adaequatio...". 
uma das suas ocasionais "hesitações". No texto do De anima, onde Elorduy indevidamente quer impor a Suarez a aceitação de um terceiro reino de realidade, a posição de Suarez vai em direção contrária quando ele fala que o universal é reale aliquid. ${ }^{44}$

Suarez se aproxima dos nominalistas no que ele recusa aceitar que os universais, ou que qualquer outra entidade, exista efetivamente e que haja um estatuto ontológico intermediário entre os entia realia e os entia rationis. Ele se aproxima dos nominalistas também no que ele, por vezes, tende a reconhecer o próprio ato mental como o suporte do sentido. Porém, as argumentações de Suarez deixam um rastro de "oscilações" entre a recusa e a tolerância em permitir uma dimensão semântico-intencional autônoma. Já mostrei em outros textos ${ }^{45}$ que esta "oscilação" ou "hesitação" (pode-se usar várias palavras aqui) não é casual nem é o resultado de uma argumentação contraditória que poderia ser melhorada, mas que se trata de uma "contradição" necessária, no sentido de que ela vem a possibilitar a sistematicidade, isto é, o fechamento da metafísica de Suarez.

\section{Referências bibliográficas}

Elorduy, E.: "El concepto objectivo en Suárez", in: Pensamiento 4, Núméro especial (1948) 335-423.

Foucault, M. Les mots et les choses Paris, Gallimard, 1966.

Müller, H. J.: Die Lehere vom verbum mentis in der Spanischen Scholastik. Untersuchungen zur historischen Entwicklung und zum Verständnis dieser Lehre bei Toletus, den Conimbricensern und Suarez (Tese de Doutorado em Filosofia) Münster 1968.

Rios, A. R. "Conceito objetivo, denominação extrínseca e entia rationis em Francisco Suarez (15481617)" in: Veritas Porto Alegre, v. 42, n. 3, Setembro 1997 p. 719-750.

Rios, A. R. "Racionalidade substancial e racionalidade acidental" in: L. A. De Boni (org.) Lógica e Linguagem Idade Média Porto Alegre, EDIPUCRS, 1995 p. 237-252.

Rios, A. R. "Verdade e adaequatio na Escolástica Tardia. Uma análise da teoria da verdade das proposições em Francisco Suarez (1548-1617)" (inédito) 57 p.

Rios, A. R. Die Wahrheit der Aussagesätze und das göttliche Wissen von zukünftig Kontingentem bei Francisco Suarez. Berlin 1991 (Tese de Doutorado) $310 \mathrm{p}$.

Suarez, Franciscus: Opera omnia, ed. c. Berton, Paris.

Abreviação:

$\mathrm{DM}=$ Suarez, Disputationes Metaphysicae, Opera omnia Vols. 25-26.

DM 8, 2,3 = DM disputação 8, seção 2, número 3.

$44 \dot{E}$ interessante notar que a passagem a que me refiro em $D e$ anima lib. 6 c. 3 n. 24 não deixa de ter sua parcela de "hesitaçäo". Analiso esta passagem em Conceito objetivo... p. 734-735.

45 Sobretudo em Rios Conceito Objetivo... 